\title{
PENGARUH MANAJERIAL KEPALA MADRASAH TERHADAP KINERJA GURU DI MA IRSYADUL ISLAMIYAH ROKAN HILIR
}

\author{
Siti Halimah \\ Sekolah Tinggi Agama Islam (STAI) Rokan Bagan Batu Rokan Hilir \\ Email: sitihalimah@stairokan.ac.id
}

Website : https://jurnal.uin-antasari.ac.id/index.php/ptkpend/index

Received: 2 Juli 2020; Accepted: 7 Juli 2020; Published: 7 Juli 2020

\begin{abstract}
One of the interesting problems to be studied in the world of education regarding human resources is teacher performance. " This research is quantitative in nature which aims to test hypotheses using statistical analysis both regression analysis and multiple regression. The most basic data collection tool is a questionnaire (questionnaire). Samples in the study of all teachers in MA Irysadul Islamiyah Rokan Hilir, amounting to 34 teachers. The results of this study found that, there was a significant influence between the managerial headmaster of madrasas on teacher performance, with the influence strength of 0.570 . The contribution made by the managerial headmaster of madrasas to teacher performance was $31.2 \%$.
\end{abstract}

Keywords: influence; managerial; principal of madrasah; teacher's performance

\begin{abstract}
ABSTRAK
Salah satu masalah yang menarik untuk dikaji dalam dunia pendidikan mengenai sumber daya manusia adalah kinerja guru.". Penelitian ini bersifat kuantitatif yang bertujuan menguji hipotesis dengan menggunakan analisis statistik baik analisis regresi maupun regresi ganda, Alat pengumpul data yang paling pokok adalah kuesioner (angket). Sampel dalam penelitian seluruh guru di MA Irysadul Islamiyah Rokan Hilir yang berjumlah 34 orang guru. Hasil penelitian ini menemukan bahwa, adanya pengaruh signifikan antara manajerial kepala madrasah terhadap kinerja guru, dengan kekuatan pengaruh sebesar 0.570. Kontribusi yang diberikan oleh manajerial kepala madrasah terhadap kinerja guru adalah $31,2 \%$.
\end{abstract}

Kata Kunci: pengaruh; manajerial; kepala madrasah; kinerja guru

\section{PENDAHULUAN}

Pada era globalisasi dewasa ini pendidikan menjadi sangat penting. pendidikan merupakan salah satu bekal yang harus dimiliki masing-masing individu agar berkembang sentunya akan menjadian individu tersebut semakin berkualitas serta mampu bersaing secara kompetitif era persaingan yang semakin ketat dan keras dalam berbagai sudut aktivitas, yaitu sumberdaya manusia yang mampu menghadapi persaingan dan terampil dalam berbagai aktivitas kehidupan (Sawaluddin, 2017)

\begin{tabular}{lcr}
\multicolumn{2}{r}{ Sumberdaya manusia } & berkualitas \\
dapat diciptakan melalui & lembaga \\
pendidikan $\quad$ madrasah & sebagai \\
penyelenggara & pendidikan & formal
\end{tabular}
(Sawaluddin, Sainab, 2019). Madrasah merupakan tempat penyelenggara pendidikan formal yang telah mendapatkan kepercayaan masyarakat dalam mempersiapkan dan menghantarkan generasi anak bangsa untuk mampu bersaing dalam kompetisi global yang terus maju dan berkembang (Sawaluddin, Sawaluddin, 2018). 
Berdasarkan Undang-undang Republik Indonesia Nomor 20 Tahun 2003 dijelaskan bahwasanya proses pendidikan secara nasional Indonesia memiliki tujuan yaitu mengembangkan potensi peserta didik, agar menjadi manusia yang beriman dan bertaqwa kepada Tuhan Yang Maha Esa, berakhlak mulia, sehat berilmu, cakap, kreatif, mandiri dan menjadi warga yang demokratis serta bertanggungjawab (Supardi, 2014).

Kualitas guru identik dengan kinerja guru. Kinerja guru adalah usaha tertingi yang di lakukan oleh guru dalam melakukan tugas tugasnya sebagai guru (Laila Hamidah, at.al, 2019). Mulyasa menjelaskan kinerja guru tidak lepas dari manajemen pendidikan yang memberikan kewenangan kepada kepala madrasah dalam melakukan perencanaan, pengorganisasian, pengawasan dan pengendalian pendidikan di Madrasah (Mulyasa,2005). Kepala Madrasah memiliki berbagai potensi yang dapat dikembangkan secara optimal, sehingga bawahannya yaitu guru dan tenaga kependidikannya dapat meningkatkan kinerjany.

Ketercapaian dan terwujudnya kinerja guru yang sangat bergantung kepada kecakapan/kemampuan manajerial kepala madrasah (Imam Musbikin, 2013). Melakukan peran dan fungsinya sebagai manajer kepala madrasah harus mampu memiliki strategi yang tepat untuk mengoptimalkan tenaga kependidikan melalui kerja sama atau kooperatif, dan medorong keterlibatan seluruh tenaga pendidik dalam berbagai kegiatan yang menunjang program madrasah (E.Mulyasa, 2011).

\section{METODE PENELITIAN}

Jenis penelitian yang digunakan dalam penelitian ini adalah menggunakan metode survei. Survei adalah metode riset dengan menggunakan kuesioner sebagai instrument pengumpulan data penelitian. Tujuannya untuk memperoleh informasi tentang sejumlah responden yang dianggap mewakili populasi tertentu (Rachman Kriyanto, 2006). Margono juga menjelaskan bahwa tujuan penelitian kuantitatif adalah untuk menguji teori, mengukuhkan fakta-fakta, dan untuk menunjukkan hubungan-hubungan di antara variabel (Rachman Kriyanto, 2006). Sedangkan menurut Sugiyono, penelitian kuantitatif bertujuan untuk mengetahui hubungan dua variabel atau lebih yang bersifat sebab akibat (kausal), menguji teori, dan analisa data dengan menggunakan statistik untuk menguji hipotesis (Sugiyono, 2008).

Penelitian ini menggunakan jenis penelitian pendekatan kuantitatif yang dimulai dengan berpikir deduktif untuk menurunkan hipotesis, kemudian melakukan pengujian di lapangan, kesimpulan atau hipotesis tersebut ditarik berdasarkan data empiris. (S. Margono, 1997) Ciri dari pendekatan penelitian kuantitatif ini adalah adanya variabel, operasional, reliabilitas, hipotesis, validitas dan makna secara statistik (S. Margono, 1997).

Berdasarkan pendapat di atas, maka dalam penelitian ini menggunakan jenis penelitian kuantitatif karena dalam penelitian ini yang akan dilakukan adalah untuk menguji hipotesis penelitian seberapa besar pengaruh Manajerial Kepala Madrasah terhadap Kinerja Guru Di Madrasah Aliyah (MA) Irsyadul Islamiyah Rokan Hilir

\section{HASIL DAN PEMBAHASAN}

Penelitian ini mengkaji faktor-faktor yang dapat brpengaruh terhadap kinerja guru di MA Irsyadul Islamiyah Rokan Hilir, banyak faktor yang dapat mempengaruhi kinerja guru namun dalam hal ini peneliti hanya mengkaji dua variabel saja yang dapat mempengaruhi kinerja guru diantarannya adalah manajerial kepala madrasah dan komunikasi kepala madrasah. Berikut ini 
akan dibahas data hasil pengukuran dari masing-masing variabel tersebut.

\section{Deskripsi Data Variabel Manajerial Kepala Madrasah}

Data variabel manajerial kepala madrasah dalam penelitian ini diperoleh melalui kuesioner yang berjumlah 19 butir pertanyaan/ pernyataan. Bobot skor setiap butir pertanyaan/pernyataan 1 sampai dengan 5. Secara teoritis skor manajerial kepala madrasah akan bervariasi antara skor minimal 19 sampai skor maksimal 95. Berdasarkan analisis data, diperoleh deskripsi statistik hasil pengukuran variabel manajerial kepala madrasah yang ditunjukkan pada tabel berikut.

Tabel 1. Deskripsi Data Variabel Manajerial Kepala Madrasah

\begin{tabular}{|l|c|}
\hline Valid & 34 \\
\hline Missing & 0 \\
\hline Mean & 70,06 \\
\hline Std. Error of Mean & 1,122 \\
\hline Median & 69,50 \\
\hline Mode & $61^{\mathrm{a}}$ \\
\hline Std. Deviation & 6,541 \\
\hline Variance & 42,784 \\
\hline Range & 22 \\
\hline Minimum & 60 \\
\hline Maximum & 82 \\
\hline Sum & 2382 \\
\hline
\end{tabular}

Dari tabel di atas dapat diketahui skor variabel manajerial kepala madrasah bervariasi dari skor terendah 60, sampai skor maksimal 82. Berdasarkan perhitungan statistika dasar diperoleh angka sebagai berikut : mean $=70,06$, median $=69,50$, modus $=61$ dan standar deviasi 6.541. Perhitungan ini menunjukkan mean dan median yang tidak jauh berbeda. Hal ini mengindikasikan bahwa skor variabel manajerial cenderung berdistribusi normal. Berikut grafik histogram distribusi frekuensi skor manajerial kepala madrasah.

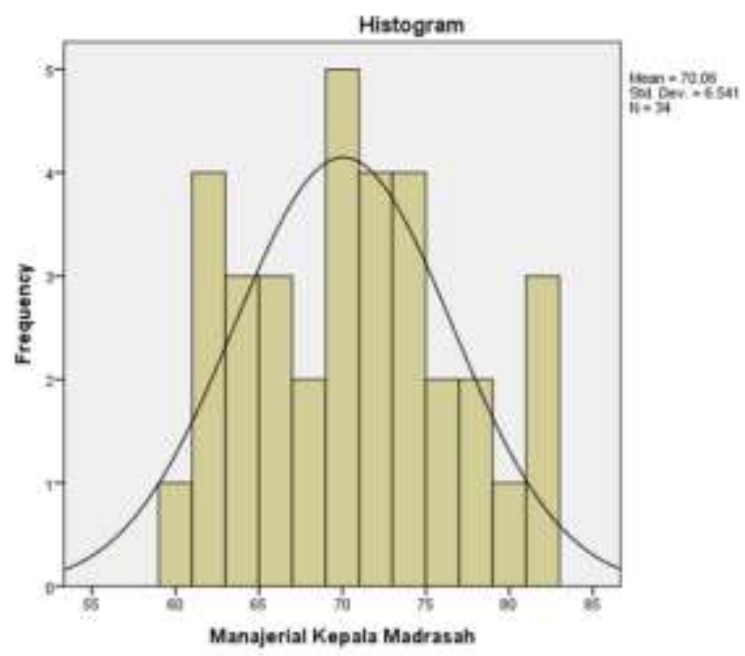

Gambar 1. Histogram Distribusi Frekuensi Skor Manajerial Kepala Madrasah $\left(\mathbf{X}_{1}\right)$

\section{Deskripsi Data Variabel Kinerja Guru}

Data variabel Kinerja Guru dalam penelitian ini diperoleh melalui kuesioner yang berjumlah 20 butir pertanyaan/ pernyataan. Bobot skor setiap butir pertanyaan/pernyataan 1 sampai dengan 5 . Secara teoritis skor kinerja guru akan bervariasi antara skor minimal 20 sampai skor maksimal 100. Berdasarkan analisis data, diperoleh deskripsi statistik hasil pengukuran variabel kinerja guru yang ditunjukkan pada tabel berikut.

Tabel 2. Deskripsi Data Variabel Kinerja Guru Statistics

\begin{tabular}{|l|c|}
\hline & 34 \\
\hline Missing & 0 \\
\hline Mean & 73,12 \\
\hline Std. Error of Mean & 1,272 \\
\hline Median & 73,00 \\
\hline Mode & 73 \\
\hline Std. Deviation & 7,417 \\
\hline Variance & 55,016 \\
\hline Range & 35 \\
\hline Minimum & 53 \\
\hline Maximum & 88 \\
\hline Sum & 2486 \\
\hline
\end{tabular}


Dari tabel di atas dapat diketahui skor variabel kinerja guru bervariasi dari skor terendah 53, sampai skor maksimal 88. Berdasarkan perhitungan statistika dasar diperoleh angka sebagai berikut : mean $=73,12$, median $=73,00$, modus $=73$ dan standar deviasi 7,417. Perhitungan ini menunjukkan mean dan median yang tidak jauh berbeda. Hal ini mengindikasikan bahwa skor variabel kinerja guru cenderung berdistribusi normal. Untuk memperoleh gambaran tentang distribusi skor kinerja guru , dalam tabel 3 disajikan distribusi frekuensi skor kinerja guru.

Tabel 3. Frekuensi Skor Kinerja Guru

\begin{tabular}{|c|c|c|}
\hline Kelas Interval & Frekuensi $(f)$ & $\begin{array}{c}\text { Persentase } \\
(\%)\end{array}$ \\
\hline 1 & 2 & 3 \\
\hline $53-58$ & 2 & $6 \%$ \\
\hline $59-64$ & 2 & $6 \%$ \\
\hline $65-70$ & 5 & $15 \%$ \\
\hline $71-76$ & 16 & $47 \%$ \\
\hline $77-82$ & 6 & $17 \%$ \\
\hline $73-88$ & 3 & $9 \%$ \\
\hline Jumlah & 34 & $100 \%$ \\
\hline
\end{tabular}

Berdasarkan distribusi frekuensi skor kinerja guru maka dibuat katagori kinerja guru dengan membagi kepada tiga kelompok, yaitu kelompok tinggi, sedang dan rendah. Berdasarkan hasil perhitungan, maka pengelompokan skor untuk variabel kinerja guru diperoleh $20 \%$ (7 orang) kelompok tinggi, 68\% (23 orang) kelompok sedang, dan $12 \%$ (4 orang) kelompok rendah. Dari sini dapat dipahami bahwa tingkat kinerja guru pada umumnya berada pada kelompok sedang. Artinya, sebagian besar guru harus lebih meningkatkan kembali kinerjanya. Berikut grafik histogram distribusi frekuensi skor kinerja guru.

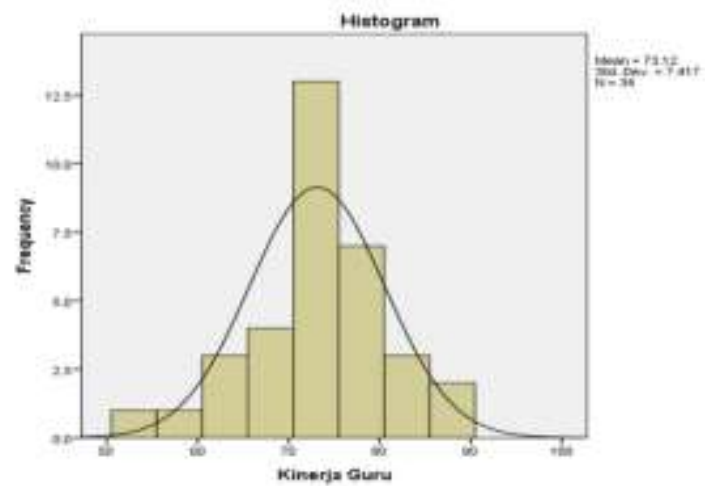

Gambar 2. Histogram Distribusi Frekuensi Skor Kinerja Guru (Y)

Hipotesis pertama yang diajukan adalah "terdapat pengaruh positif manajerial kepala madrasah terhadap kinerja guru di MA Hidayatul Mubtadiin Jati Agung". Berdasarkan hasil perhitungan dengan menggunakan korelasi Product Moment dari Pearson, maka dapat dirangkum hasil analisisnya pada tabel 20 berikut :

Tabel 4. Correlations Product Moment Manajerial Kepala Madrasah dengan Kinerja Guru

\begin{tabular}{|c|c|c|c|}
\hline & & $\begin{array}{c}\text { Manajerial } \\
\text { Kepala } \\
\text { Madrasah }\end{array}$ & $\begin{array}{l}\text { Kinerja } \\
\text { Guru }\end{array}$ \\
\hline $\begin{array}{l}\text { Manajerial Kepala } \\
\text { Madrasah }\end{array}$ & $\begin{array}{l}\text { Pearson } \\
\text { Correlation } \\
\text { Sig. (2-tailed) } \\
\mathrm{N} \\
\text { Pearson } \\
\text { Correlation } \\
\text { Sig. (2-tailed) } \\
\mathrm{N}\end{array}$ & $\begin{array}{c}1 \\
34 \\
.559^{* *} \\
.001 \\
34\end{array}$ & $\begin{array}{c}.559 * \\
.001 \\
34 \\
1 \\
\\
34\end{array}$ \\
\hline
\end{tabular}

Tabel 5. Hasil Analisis Hubungan Manajerial $\left(\mathbf{X}_{1}\right)$ dengan Kinerja Guru (Y)

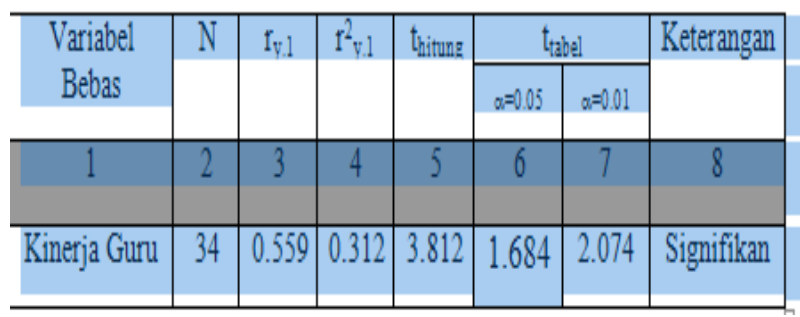


Pada tabel di atas didapat harga $t_{\text {hitung }}$ sebesar 3.812 yang lebih besar dari $\mathrm{t}_{(34)(0.05)}$ sebesar 1.684 dan $\mathrm{t}_{(34)(0.01)}$ sebesar 2.074. Hal ini menunjukkan bahwa hubungan antara Manajerial dengan Kinerja Guru signifikan. Kekuatan hubungan antara Manajerial dengan Kinerja Guru signifikan adalah sebesar 0.570. Hasil analisis juga menunjukkan bahwa koefisien determinasi sebesar 0.312 berarti bahwa pengaruh Manajerial Kepala Madrasah terhadap Kinerja Guru adalah $31,2 \%$. Hal ini berarti bahwa $\mathrm{H}_{\mathrm{a}}$ yang menyatakan terdapat pengaruh yang signifikan dari Manajerial Kepala Madrasah terhadap Kinerja Guru di MA Irsyadul Islamiyah Rokan Hilir diterima, konsekuensinya $\mathrm{H}_{0}$ ditolak.

\section{PENUTUP}

Berdasarkan hasil penyajian dan analisis data, maka sesuai dengan rumusan masalah yang diajukan dalam penelitian ini diperoleh beberapa kesimpulan sebagai berikut:

Adanya pengaruh antara manajerial kepala madrasah dan kinerja guru yang signifikan dan positif, dengan kekuatan hubungan pengaruh sedang sebesar 0.570 . Kontribusi yang diberikan oleh manajerial kepala madrasah terhadap kinerja guru adalah 31,2\%. Ini menunjukkan bahwa manajerial kepala madrasah akan meningkatkan kinerja guru apabila keefektifan manajerial kepala madrasah yang didukung oleh guru dan staf lainnya.

\section{DAFTAR PUSTAKA}

E.Mulyasa, Menjadi Kepala Sekolah Profesional, Bandung: PT. Remaja Rosda Karya, 2011

Imam Musbikin, Menjadi Kepala Sekolah yang Hebat, Pekanbaru: Zanafa Publishing 2013

Laila Hamidah, Sawaluddin Siregar, Nuraini Nuraini, Kepribadian Guru Pendidikan Agama Islam Menurut Buya Hamka, Tarbiyah: Jurnal Ilmiah Kependidikan e-ISSN: 2548-
8376 Vol. 8 No. 2 Juli - Desember $2019(135-146)$

M. Chabib Thaha, Tehnik-tehnik Evaluasi Pendidikan (Jakarta: PT Raja Grafindo, 1990), hlm. 35

Mulyasa, Kurikulum Berbasis Kompetensi : Konsep, Karakteristik, dan Implementasi. Bandung : Remaja Rosda Karya, 2005

Rachman Kriyanto, Tekhnik Praktis Riset Komunikasi, Jakarta: Kencana Pranada Media Group, 2006

S.Margono,MetodologiPenelitianPendidik an, Jakarta: Rineka Cipta, 1997

Sawaluddin, Potensi Indra, Akal, dan Kalbu Menurut Al-Qur'an dan Aplikasinya Dalam Pengembangan Pendidikan Dasar, Pekanbaru: UIN Suska Riau, Disertasi, 2017, pp. 402-404

Sawaluddin, Sainab, the Intelligent Meaning In The Qur'an: Nalysis Of The Sure Potential In The Al-Qur'an As A Dimension Of Human Psychic Insaniah, Jurnal Madania: Volume 9 : 2, 2019 (e-ISSN 2620-8210 | pISSN pp. 373-395

Sawaluddin, Sawaluddin. "Konsep Evaluasi Dalam Pembelajaran Pendidikan Islam." Jurnal Pendidikan Agama Islam AlThariqah 3, No. 1 (July 13, 2018): 39. Doi:10.25299/ Althariqah. 2018.Vol3 (1).39-53

Slameto, Evaluasi Pendidikan, (Jakarta: Bumi Aksara, 2001), hlm. 54

Sugiyono, Metode Penelitian Pendidikan Pendekatan Kuantitaif, Kualitatif dan R\&D, Bandung: Alfabeta, 2008

Supardi, Kinerja Guru, Jakarta : Rajawali Pers, 2014.

Zainal Arifin, Evaluasi Pembelajaran (Prinsip, Teknik, Prosedur), Cetakan ketiga (Bandung; PT. Remaja Rosdakarya, 2011), hlm. 153-177 